\title{
Priorities for nutrition interventions in reproductive health: a bilateral agency perspective
}

\author{
BY FRANCES R. DAVIDSON \\ US Agency for International Development, Office of Health and Nutrition, Washington, DC \\ 20523-1808, USA
}

Each year over half a million women in low-income countries die from complications associated with childbearing. Millions more suffer pregnancy-related morbidities and chronic long-term disabilities related to pregnancy and childbirth. These compromise a woman's health and well-being and her ability to play an active role in her country's development. Many of these problems have their roots in poor nutritional status (World Bank, 1993).

It has often been said that the actual time of gestation is not a discrete 9 months but in fact a generation's experience, that is, at least 20 years. Statistical analysis reveals that: women who give birth before age 18 years are three times more likely to die in childbirth than those who give birth between ages 20 and 29 years; for women over 34 years, the risk of maternal mortality is five times as high; first births are often riskier than second or third births, but, as parity rises, the risk of maternal mortality also increases. Almost $30 \%$ of pregnancies end in abortion, giving a total of about fifty-five million abortions in the world each year; most of these are performed under unsafe conditions. As a result, about 60000 women per year are estimated to die from unsafe abortions (World Bank, 1993).

The International Safe Motherhood Conference held in February 1987 in Nairobi, Kenya, launched the Safe Motherhood Initiative with the challenge 'Where is the M in the MCH?' (where MCH represents mother and child health). Nearly 7 years later we are still asking the same question, despite the fact that many agencies including our own have identified reproductive health as an emphasis area for funding of programmes.

Recent international conferences including the 1990 World Summit for Children and the International Conference on Nutrition (ICN) in 1992 (US Agency for International Development, 1992), identified several goals to be achieved by signatory countries by the year 2000. Specific attention to the situation of women is included in these, i.e. reduction of the maternal mortality rate by half; reduction of Fe-deficiency anaemia in women to two-thirds of the 1990 levels; special attention to the health and nutrition of pregnant and lactating women; access for all women to prenatal care, trained attendants during childbirth, and referral for high-risk pregnancies and obstetric emergencies; maintenance of a high level of immunization coverage against tetanus for women; empowerment of all women to breast-feed their children; access by all couples to information and services to prevent unwanted and unsafe pregnancies; reduction in the adult illiteracy rate to at least half the 1990 level, with emphasis on female literacy (US Agency for International Development, 1992).

\section{WHERE ARE WE IN ACHIEVING THESE GOALS?}

At the ICN in 1992 (US Agency for International Development, 1992) one of the major policy guidelines of the Plan of Action for Nutrition adopted was focus on women and 
gender equality. The guideline states 'Women are inherently entitled to adequate nutrition in their own right as individuals. Special attention should be given to the nutrition of women during pregnancy and lactation. All forms of discrimination including detrimental traditional practices against women must be eliminated in accordance with the 1979 Convention on Elimination of All Forms of Discrimination Against Women'. Also encouraged is the concept of women's health which spans the life-cycle, rather than the more limited focus on the reproductive period.

\section{WHAT HAS BEEN DONE SINCE THE INTERNATIONAL CONFERENCE ON NUTRITION TO PROMOTE THIS GUIDELINE?}

Conservative calculations suggest that among the 1130 million women aged 15 years or older living in developing countries in 1989 , over 500 million were anaemic due to $\mathrm{Fe}$ deficiency, almost 500 million were stunted as a result of childhood protein-energy malnutrition, about 250 million were at risk of disorders due to severe I deficiency (with 100 million having frank goitres), and almost two million were blind due to vitamin $\mathrm{A}$ deficiency (Leslie, 1991, 1992).

\section{HOW IS MATERNAL MORTALITY LINKED TO MATERNAL NUTRITIONAL STATUS?}

Malnutrition in women is undoubtedly a problem insufficiently recognized and inadequately documented. To date, the emphasis in discussing women's health and nutrition has been on their role as mothers. A review that we carried out on programmes aimed at improving women's health status revealed that the indicator used, almost without exception, for documenting this impact was the nutritional status of the child. Women were not measured at baseline or at the end of the programme. For the first time, women's nutritional status as a separate category was included in The United Nations Subcommittee on Nutrition's report on the World Nutrition Situation, 1993 (United Nations Administration and Coordination Committee/Subcommittee on Nutrition, 1993). We hope that the database on women's health used for this report will be used to assess progress towards reaching goals for women's health status improvement.

\section{WHERE IN US AGENCY FOR INTERNATIONAL DEVELOPMENT (USAID) ARE WE ADDRESSING WOMEN'S HEALTH AND NUTRITION?}

USAID has undergone a major re-organization in the last year under the leadership of USAID administrator, Brian Atwood. Besides the regional bureaux for Africa, Asia, Latin America and the Caribbean; and now the new bureau for newly-independent states of the former Soviet Union, the global office in Washington which provides field support and technical assistance has been re-organized into five centres of excellence: democracy, economic growth, environment, human resources and population, health and nutrition.

The newly-established Population, Health and Nutrition Center in the Bureau for Global Programs, Field Support and Research will facilitate coordinated programming across all of the sectors of USAID as well as synergistic approaches to implementing reproductive health activities. The new Center has three offices: the Office of Popu- 
lation, a combined Office of Health and Nutrition and a new Office of Field and Program Support. These offices manage a large portfolio of technical assistance, training, communications and research projects which support field missions and supplement and complement on-going bilateral programmes.

The USAID Administrator, Brian Atwood, is deeply committed to making USAID's programmes more responsive to the needs of women and to improving women's reproductive health. In a recent speech made to the Central Council of the International Planned Parenthood Federation, he said: 'Our concern must be to meet the unmet need for family planning and go beyond. Maternal health, prenatal care, safe sex and social education must be part of the total picture. So must the empowerment of women. So must the education of girls'.

USAID, in common with other agencies, has spent some time recently in defining its programme in reproductive health. Our definition is: 'the ability of men and women to achieve their reproductive intentions while maintaining physical, mental and social well-being'. Reproductive health includes the ability to ensure that desired pregnancies result in successful outcomes for both parents and infant; and that sexual expression is free from undesired pregnancy, disease and coercion. Reproductive health is comprehensive and spans 'life phases' throughout men's and women's lives. The decisions men and women make about reproductive health should be informed, voluntary, safe, certain, responsible and actionable.

USAID's definition is not dissimilar to that of the World Health Organization (1993) for reproductive health: a condition where the reproductive process is accomplished in a state of complete physical, mental and social well-being and not merely the absence of disease or disorders of the reproductive process.

Transforming these definitions into programmes is the real challenge, especially for a development agency. All too frequently, the way in which this has been approached is with an emphasis on cure instead of prevention and care. And this is the point where activities aimed at improvement of reproductive health and nutrition have separated. (And this is why perhaps reproductive health activities and nutrition activities have not been more closely joined.) Integrating the life-cycle preventive aspect of nutrition activities into those aimed at improving reproductive health will result in more effective programmes. The disjuncture is counterproductive for development. How can programmes aimed at improving reproductive health be more preventative in nature such that nutrition can play a greater role in a woman's well-being?

USAID's strategy for population, health and nutrition comprises: promoting the rights of couples and individuals to determine freely and responsibly the number and spacing of their children; improving individual health, with special attention to the reproductive health needs of women and adolescents and the general health needs of infants and children; reducing population growth rates to levels consistent with sustainable development; making programmes responsive and accountable to the end-user.

USAID's reproductive health programme has three major priorities: family planning and related fertility services; safe pregnancy services, breast-feeding, and the improvement of women's nutritional status in order to decrease maternal morbidity; prevention and management of sexually-transmitted diseases (STD) and human immunodeficiency virus (HIV).

Previously, the separation of family-planning services from other health care for women has compromised their ability to benefit from them. New strategies and priorities 
have the potential for integrating preventive aspects of reproductive health. There is no need to assume that couples are already sexually active, adolescents and young women are already pregnant and malnourished and that men and women are already infected with STD or HIV. Indeed, in country-based programmes we are actively assuring that when people come for family-planning services, other related needs are also addressed. This has been found particularly effective in treatment of STD.

How are USAID's activities in population, health and nutrition related to the three major priorities? Several USAID programmes make an impact on women's reproductive health (ICRW, 1990; Mothercare, 1990a, $b$, 1993a, $b$; Institute for Reproductive Health, 1993; US Agency for International Development, 1993a,b,c, 1994a,b,c; Women's and Infants' Nutrition Project, 1994).

Examples of population programmes include: family-planning training for paramedical, auxiliary and community personnel, helping to build capacity in developing countries; central contraceptive procurement provides an efficient mechanism for consolidating purchases of contraceptives for use worldwide; training in modern reproductive health knowledge and skills for selected health providers in voluntary sterilization, intra-uterine devices, injectables and implants; access to family planning through women, trains women to manage services and improve access to quality care; contraceptive social marketing utilizes techniques and resources of commercial enterprises to increase the availability and use of contraceptives among low- and middleincome groups.

Some health programmes are: global programme on acquired immune deficiency syndrome (AIDS) provides technical support and policy leadership in the global fight against HIV and AIDS; STD diagnostics initiative is an effort to identify, develop, field test, and assist with technology transfer of rapid, simple, inexpensive STD diagnostic tests for use in resource-limited settings; vaccine development and health research provides technical assistance to develop new and improved vaccines to reduce the incidence of major preventable diseases; vector biology and control is designed to create more effective and cost-efficient tropical-disease control programmes.

USAID's nutrition activities related to providing safe pregnancy services include: surveys on the use of prenatal care by young women and adolescents in eight countries; demonstration projects on improving maternal nutritional status in sixteen countries; training of TBA to distribute Fe-folate tablets; prenatal education and follow-up in child survival projects; technical assistance to develop plans to reduce maternal mortality in several countries.

Activities related to improving women's nutritional status include: surveys on maternal nutritional status in ten countries; field support for women and infant nutrition; operations research on adolescent nutrition in eleven countries; a clearing house for global information dissemination; global programmes to eliminate vitamin $\mathrm{A}, \mathrm{Fe}$ and I deficiency; improvement of the nutritional benefit of food for work programmes for women.

How does one integrate nutrition and reproductive health? Programmes need to go beyond the global aim of reducing fertility and mortality. Family planning and health services need to be integrated to offer related services at one site. Adolescent girls should be included in supplementary-feeding programmes before malnutrition becomes a causative factor in maternal mortality. The nutrition component of existing prenatal programmes needs to be strengthened. The impact or outcome of interventions need to 
be measured in terms of maternal anthropometry instead of just infant survival. (All programmes need to be more gender-sensitive.) They need to enhance the ability of the women to manage their own health and nutrition problems.

The condition of women is critical to the reproductive situation, both the actual birth and the child's nurturing. Programmes concerned with reproductive health would do well to include activities which support the nutritional well-being of the child and adolescent. It would appear to be common sense that the earlier the intervention the more assured one can be that the results will be positive for both mother and child. However, we lack concrete examples of this which would attract policy makers' attention. Development of 'profiles', a way of documenting the economic benefits of nutrition activities, has helped in advocacy. We know that women's social status and that of their health and nutrition are intricately intertwined. And it is clear that a woman's health and well-being translate directly into the health and well-being of her child, particularly at the critical early period after birth. In turn, women's health and nutritional status are obviously affected by existing social, economic and cultural systems. Increased access to productive resources affects food availability at the household level and this in turn is an outcome of many complex interrelated factors such as income, control over resources and educational opportunities.

The consequences of malnutrition, in all its forms (both micronutrients and macronutrients) can be seen in poor birth outcomes and poor breast-feeding and other infant feeding and care practices. A woman's success in performing functions, including child rearing leads to increased self confidence which is of great significance for tackling problems women face in the particularly difficult environment of low-income countries. Better nutrition has been shown to lead to reductions in burdens of both an economic and financial nature for women. We need to ensure that interventions to improve household food security and nutrition and health actively engage women.

Every opportunity to focus on women's reproductive health issues should be taken advantage of. In September 1994 the world focused on population at the International Conference on Population and Development in Cairo. Delegates to the conference debated the relative importance of various population and reproductive health issues and made influential policy recommendations. Issues concerning women such as nutrition, contraceptive use, childbearing and STD deserve special attention. International agencies are being encouraged to participate actively in the Fourth World Conference on Women to be held in Beijing, in 1995. They have been asked to provide documentation for this conference on the importance of women's and young girls' nutritional well-being and health not only for their own development, but for the social and economic development of their countries. This will provide donor organizations such as USAID with the necessary documentation to properly assess areas of programme need. It will also allow us to measure progress, through careful monitoring, toward achievement of the goals for improving women's health and nutrition that have been set in recent forums.

\section{REFERENCES}

ICRW (1990). Better Health for Women: Research Results from the Maternal Nutrition and Health Care Program.

Institute for Reproductive Health (1993). Technical Progress Report.

Leslie, J. (1991). Women's nutrition: the key to improving family health in developing countries? Health Policy and Planning 6, 1-19. 
Leslie, J. (1992). Women's lives and women's health: using social science research to promote better health for women. Journal of Women's Health 1, 307-318.

MotherCare (1990a). Behavioral Determinants of Maternal Health Care Choices in Developing Countries. Working Paper no. 2. Washington, DC: USAID.

MotherCare (1990b). Interventions to Improve Maternal and Neonatal Health and Nutrition. Working Paper no. 4. Washington, DC: USAID.

MotherCare (1993a). Lessons Learned 1989-1993. Summary Final Report. Washington, DC: USAID.

MotherCare (1993b). Country Project Descriptions 1989-1993. Washington, DC: USAID.

United Nations Administration and Coordination Committee/Subcommittee on Nutrition (1993). Second Report on the World Nutrition Situation. Vol. 1. Global and Regional Results. Geneva: ACC/SCN.

US Agency for International Development (1992). International Conference on Nutrition. World Declaration and Plan of Action for Nutrition, Rome, December 1992. Washington, DC: USAID.

US Agency for International Development (1993a). Child Survival. An Eighth Report to Congress on the USAID Program. Washington, DC: USAID.

US Agency for International Development (1993b). PVO Child Survival Grant Program. First Annual Report. Dhaka Urban Integrated Child Survival Project, Bangladesh. Washington, DC: USAID.

US Agency for International Development (1993c). Opportunities for Micronutrient Interventions Project Paper. Washington, DC: USAID.

US Agency for International Development (1994a). Breastfeeding: An Update on USAID Activities. Washington, DC: USAID.

US Agency for International Development (1994b). Nutrition Education and Social Marketing Field Support Project. Final Evaluation. Washington, DC: USAID.

US Agency for International Development (1994c). Women in Development. Report. FYs 1991 and 1992. Washington, DC: USAID.

Women's and Infants' Nutrition Project (1994). Women's and Infants' Nutrition Project. Mid-term Evaluation. Washington, DC: USAID.

World Bank (1993). World Development Report 1993. New York: Oxford University Press.

World Health Organization (1993). Technical Working Definition of Reproductive Health in FHE. WHOTERM Abstract. WHO-TermWatch O2. Geneva: WHO. 